\title{
Comparison of statistical methods for outlier detection in proficiency testing data on analysis of lead in aqueous solution
}

\author{
Sushree SwarupaTripathy ${ }^{*}$, Rajiv Kumar Saxena, Prabhat Kumar Gupta \\ Analytical Chemistry, Sophisticated Analytical Support Division, CSIR- National Physical Laboratory, Dr K. S. Krishnan Marg, New \\ Delhi-110012, INDIA
}

\section{Email address:}

tripathyss@mail.nplindia.org (S. S. Tripathy)

\section{To cite this article:}

Sushree SwarupaTripathy, Rajiv Kumar Saxena, Prabhat Kumar Gupta. Comparison of Statistical Methods for Outlier Detection in Proficiency Testing Data on Analysis of Lead in Aqueous Solution. American Journal of Theoretical and Applied Statistics.

Vol. 2, No. 6, 2013, pp. 233-242. doi: 10.11648/j.ajtas.20130206.21

\begin{abstract}
Proficiency testing is the regular testing of the performance of individual laboratories by an external agency. Stable and effectively homogeneous elemental solutions of different concentrations ranging were prepared at NPL and were certified by round robin test. These certified reference materials (CRMs) along with reports containing all information, where the laboratories were identified only by a reference number were being distributed to sixty seven participant laboratories. In this paper the data of lead $(\mathrm{Pb})$ elemental solution of $1-5 \mathrm{mg} / 1$ is only presented for outlier detection. The results received from the sixty four numbers of laboratories for $\mathrm{Pb}$ elemental solution statistically evaluated with different approaches viz. Cochran's test, Grubb's test, Hampel's test, classical z-score, median and NIQR method, robust statistical analysis : Algorithm A (ISO 13528) and NATA method. The robust estimate of average and uncertainty values derived from ISO 13528 method are very close to the reference value for the 1 and $2 \mathrm{mg} / \mathrm{l}$ of Pb elemental solutions. The performance of the laboratories was expressed by $\mathrm{z}$-score and the laboratories having $|\mathrm{z}| \leq 2$ are classified as satisfactory, $2<|\mathrm{z}| \leq 3$ are classified as questionable and $|z|>3$ are considered as unsatisfactory. Among all the methods, the highest number of outlier i.e. about $30 \%$ obtained by NATA statistical analysis. As NATA method considers variance in both within and between laboratory results so it seems to be the most suitable method for outlier detection for the present data set evaluated in this study.
\end{abstract}

Keyword: Proficiency Testing, Statistical Analysis, Z-Score, Outlier

\section{Introduction}

Growth in world trade has shown the ways to remove the technical barrier so that the goods can cross the frontiers without delay and added cost. The importing economy needs to ensure the quality of the product being imported as per their requirement. It should have full confidence in the technical competence of the exporter or their testing laboratory. The quality assurance and quality control of the product could be achieved by implementation of ISO/IEC 17025 [1] and use of certified reference materials in calibration of analytical equipment and validation of test methods is mandatory. Third party accreditation and participation in proficiency testing (PT) program enhance global acceptance of test reports.

According to ISO/IEC 17025, participation in proficiency testing programs or other inter laboratory comparisons is mandatory part of a laboratory's quality control procedures. PT program is an independent and unbiased technique to assess the capability of the laboratory to perform specific test or measurement within desired uncertainty limits [2-6]. Generally PT organizer gives a wide publicity about the details of the program including characteristics of the test to be undertaken to attract the attention of testing laboratory. PT organizer prepared or got prepares the material under their control or some time certified reference materials could also be used in PT program. After ensuring the stability and homogeneity of the test material, it was sent to each participating laboratories with a code number along with protocol of 
analysis, instructions and format of the test report. Each participating laboratory carried out analysis of the characteristics of the test material and reports the results on given format within fixed deadline. The data of the participants has to be compiled and statistically computed to calculate the values to assess the quality of the performance of the laboratories and to provide a score to the participant laboratories.

Certified reference materials of $\mathrm{Pb}, \mathrm{Cr}, \mathrm{Zn}$ mono elemental solutions of different concentration have been distributed to $67 \mathrm{NABL}$ accreditated laboratories for measurement of metal in water under the PT program carried out by the NPL-I. In this paper detailed of statistical analysis and description of the PT programme has been presented for $\mathrm{Pb}$ elemental solution of different concentrations ranging from 1-5 mg/l. Results obtained were evaluated by different statistical approaches viz. Cochran's test, Grubb's test, Hampel's test, classical zscore, Median and NIQR method, robust statistical method and NATA method to establish the best method to present the performance of the participant along with the outlier detection. When the number of data is more and there is a great difference between the laboratories results, in that case the detection of outlier is a tough job. Thus, in the present paper emphasis has been given to establish a suitable method to find out the outlier in such a way that the extreme values provided by some PT participants would not influence the results of the participants close to the reference value.

$\mathrm{Z}$-score is the performance score of one laboratory with the other laboratories. The quality of the measurement increases with the decrease in the $z$-score value. In this study the laboratories having $z$-score value between \pm 2 to \pm 3 are considered as questionable are advised to take close look at their results to rectify the fault. The cut off value of z-score evaluated by any method is selected as outside the range of \pm 3 which indicates there is a problem with the measurement.

\section{Statistical Techniques}

The statistical evaluation of the data obtained from the participants has been illustrated in this paper using both numerical technique such as Cochran's, Grubb's, Hampel's statistic and graphical techniques such as classical z-score, Median \& NIQR, ISO 13528: Algorithm A, NATA statistical method [4-6].

\subsection{Cochran's Test}

According to ISO 5725-2, Cochran's test is recommended for the detection of outliers in a given set of intra laboratory variability test. It is a one - sided outlier test as the criterion of the test examines only the greatest standard deviation and allows to eliminate the problematic result with the within laboratories reproducibility / repeatability.

Cochran's statistic $\mathrm{C}$ is calculated using the following formula

$$
C=\frac{S D_{\max }^{2}}{\sum_{j=1}^{p} S D_{j}^{2}}
$$

where,

SDmax is the maximum standard deviation among the investigated laboratories

SDj is the standard deviation of data from the laboratory

$p$ is the number of participated laboratories

The calculated $\mathrm{C}$ value can be compared with the critical value for a given $\mathrm{n}$ value i.e. the number of results given by each laboratory.

\subsection{Grubb's Test}

Grubb's test detects the outlier in the inter laboratory variability test in a given set of result differing significantly from others. In the Grubb's test the highest and smallest values in the set of results $\left(X_{j}\right.$ where $\left.j=1,2, \ldots \ldots \ldots \ldots . . p\right)$ are to be tested for outlier.

The value of parameter $G_{p}$ can be calculated for the largest value in the set is given as follows

$$
G_{p}=\frac{X_{p}-\bar{X}}{S D}
$$

where,

Gp is the Grubb's statistics for highest value in the set of result

$\mathrm{X}_{\mathrm{p}}$ is the highest value

$\bar{X}$ is the mean value

$\mathrm{SD}$ is the standard deviation

$\mathrm{G}_{\mathrm{p}}$ value can compare with the critical value for the " $p$ " number of laboratories

$\bar{X}$ and SD can be calculated as

$$
\begin{gathered}
\bar{X}=\frac{1}{p} \sum_{j=1}^{p} X_{j} \\
S D=\sqrt{\frac{1}{p-1} \sum_{j=1}^{p}\left(X_{j}-\bar{X}\right)^{2}}
\end{gathered}
$$

Grubb's statistics for the lowest value in the set of result can be calculated as follows

$$
G_{l}=\frac{\bar{X}-X_{l}}{S D}
$$

$\mathrm{X}_{1}$ is the lowest value 


\subsection{Hampel's Test}

The Hampel's test [6] can be performed as

$$
r_{i}=\left(x_{i}-M_{e}\right)
$$

$M e$ is the median of the data set

$\mathrm{r}_{\mathrm{i}}$ is the deviation from the median value

$x_{i}$ is the $\mathrm{i}^{\text {th }}$ data of the data set where $\mathrm{i}=1$ to $\mathrm{p}$, number of all results

The outlier value from the data set can be obtained by comparing the $r_{i}$ value from the condition given below

$$
\left|r_{i}\right| \leq 4.5 M_{e} r_{i}
$$

$M_{e} r_{i}$ is the median for deviation

\subsection{Z-Score Analysis}

The z-score is the score given to the participant as per their performance.

The classical z-score can be calculated as follows

$$
z=\left(X_{l a b}-X_{\text {mean }}\right) / S D
$$

where,

$\mathrm{X}_{\mathrm{lab}}$ is the result of the individual laboratory

$\mathrm{X}_{\text {mean }}$ is the mean value of the analyte obtained by the participants result

SD is the standard deviation of the data

To simplify the interpretation of the z-scores, the following agreements were made as

$|z| \leq 2$ imply the result is satisfactory

$2<|z| \leq 3$ imply the result is questionable

$|z|>3$ imply the result is unsatisfactory

The robust $\mathrm{z}$-score obtained by median \& normalized inter quartile range (NIQR) method can be calculated as follows

$$
z=\left(X_{l a b}-X_{\text {median }}\right) / S D_{N I Q R}
$$

where,

Xlab is the result of the individual laboratory

$\mathrm{Xmedian}$ is the median value of the analyte

SDNIQR is the normalized inter quartile range of the data set

The $\mathrm{z}$-score is interpreted in the similar way as described above

\subsection{ISO 13528: Robust Analysis Algorithm A}

The robust statistics can be calculated according to ISO 13528: Robust analysis Algorithm A. The robust average $\left(x^{*}\right)$ and the standard deviation value $\left(s^{*}\right)$ of the results of the participants could achieve by an iterative calculation as described in ISO 13528 and is not affected by the results far from the reference value. The flow chart of the algorithm is shown in schematic diagram 1.

There are $p$ data from participants: $x_{1}, x_{2}, \ldots, x_{i}, \ldots, x_{p}$

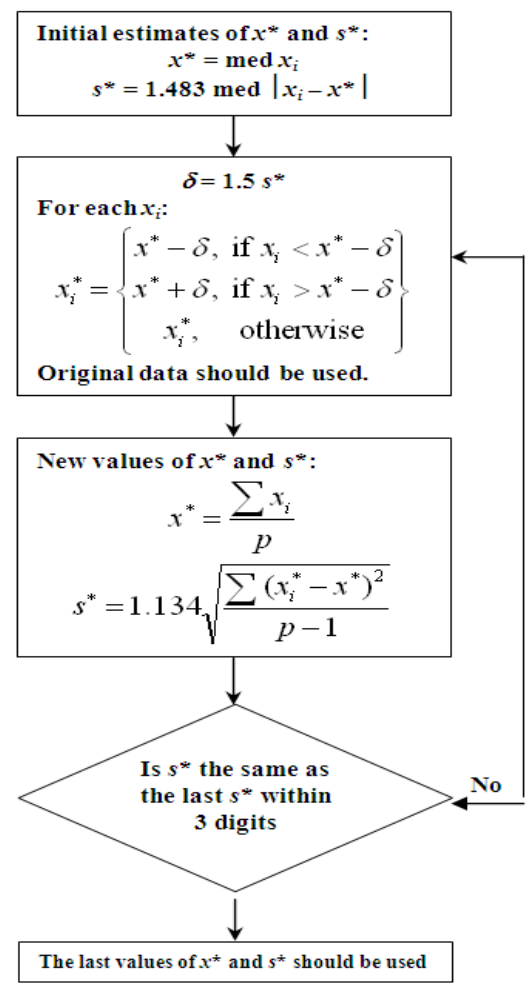

Schematic diagram 1. Flow chart of robust analysis algorithm A.

The assigned value of the analyte is the robust average value and the standard uncertainty $(\mathrm{uX})$ of the assigned value of the analyte can be estimated using the robust standard deviation as follows

$$
u X=1.25 \times s^{*} / \sqrt{p}
$$

Using the assigned value and the robust standard deviation the outlier detection may be assessed according to the $\mathrm{z}$-score value.

\subsection{NATA Method}

The process of the performance evaluation of the participating laboratories is illustrated by the z-score values of the results obtained in the PT program in accordance to the National Association of Testing Authorities, Australia (NATA) guidelines [4]. The values of standardized sum $\left(S_{i}\right)$ and standardized difference $\left(D_{i}\right)$ between two results of laboratory " $\mathrm{i}$ " have been calculated using equations (11) and (12).

$$
\begin{gathered}
S_{i}=\left(A_{i}+B_{i}\right) / \sqrt{2} \\
D_{i}=\left(A_{i}-B_{i}\right) / \sqrt{2} \text { if median }\left(A_{i}\right)>\operatorname{median}\left(B_{i}\right)
\end{gathered}
$$


Whereas $A_{i}$ and $B_{i}$ are the two measurement values of the laboratory ' $\mathrm{i}$ '

Using the values of $S_{i}$ and $D_{i}$ the values of both the Zscores i.e within the laboratory (Zwi) and Z-score between the laboratories (Zbi) can be calculated using equations (13) and (14).

$$
\begin{array}{r}
Z b i=\frac{S_{i}-\operatorname{Median}\left(S_{i}\right)}{\operatorname{IQR}\left(S_{i}\right) \times 0.7413} \\
Z w i=\frac{D_{i}-\operatorname{Median}\left(D_{i}\right)}{\operatorname{IQR}\left(D_{i}\right) \times 0.7413}
\end{array}
$$

The interquartile range (IQR) is the difference between the lower and upper quartiles of data. The lower quartile (Q1) is the value below, which a quarter of results laid and the upper quartile (Q3) is the value above, which a quarter of results laid. The quartiles are calculated analogously to the median and $\mathrm{IQR}=\mathrm{Q} 3-\mathrm{Q}$. The term "Normalized IQR" is comparable to a standard deviation and equals to IQR $x$ 0.7413. The factor 0.7413 comes from the standard normal distribution, which has a mean of zero and a standard deviation equal to one. The width of the interquartile range of such distribution is 1.34898 and $1 / 1.34898=0.7413$. $z$-score values $Z$ bi and $Z$ wi of laboratory "i" are the robust z-score of its $S_{i}$ and $D_{i}$ values. Finally each participating laboratory will be assigned with two z-score values on the basis of their results. Generally laboratories having the value of any zscore value outside the range \pm 3 are considered to be the outlier laboratories by NATA.

\section{Sample Details of PT}

The solutions provided to the laboratories are the certified reference materials [named as Bharatiya Nirdeshak Dravyas (BNDs)] which had been certified with a reference value by round robin testing. Instruments like atomic absorption spectrometer (AAS), Inductively Coupled Plasma - Atomic emission spectrometer (ICP-AES) and Inductively Coupled Plasma -Mass spectrometer (ICPMS) had been used for the analysis of these BNDs. Three numbers of elemental solutions (viz. $\mathrm{Pb}, \mathrm{Cr}$ and $\mathrm{Zn}$ ) of different concentration had been sent to 67 nos. of laboratories. In this paper only one metal i.e. Pb elemental solutions of $1-5 \mathrm{mg} / 1$ concentration is considered and evaluated the results of the participants with different statistical methods. $\mathrm{Pb}$ elemental solutions of 1,2 and 5.01 $\mathrm{mg} / 1$ were sent to 11,34 and 22 numbers of laboratories respectively. Out of thirty four numbers of laboratories in case of $2 \mathrm{mg} / \mathrm{l} \mathrm{Pb}$ solution, three numbers of laboratories did not acknowledge the receipt of the solution while other participants have been provided the results in triplicates. Details of the sample sent to various participating laboratories and results received from them are given in table 1. The participant laboratories have used different analytical techniques such as AAS-Flame, AAS-Graphite Furnace, ICP-AES, ICP-MS, APHA-3111B method, APHA-3500D method and IS-3025 method to determine the concentration of $\mathrm{Pb}$ elemental solutions.

\begin{tabular}{|c|c|c|c|c|}
\hline $\begin{array}{l}\text { Sl. } \\
\text { No. }\end{array}$ & $\begin{array}{c}\text { Metal Solution } \\
\text { Sent (Marked as } \\
\text { C) }\end{array}$ & $\begin{array}{c}\text { Lab } \\
\text { Code } \\
\text { Number }\end{array}$ & $\begin{array}{l}\text { Mean } \\
\text { Value } \\
(\mathrm{mg} / \mathrm{l}) \\
\end{array}$ & $\begin{array}{c}\text { Standard } \\
\text { Deviation } \\
(\mathrm{mg} / \mathrm{l}) \\
\end{array}$ \\
\hline 1 & & 1 & 1.02 & 0.01 \\
\hline 2 & & 2 & 1.03 & 0.01 \\
\hline 3 & & 3 & 1.05 & 0.01 \\
\hline 4 & & 4 & 1.04 & 0.02 \\
\hline 5 & CRM: BND & 5 & 1.27 & 0.07 \\
\hline 6 & 101.04 & 6 & 1.75 & 0.01 \\
\hline 7 & {$[\mathrm{~Pb}]=1 \mathrm{mg} / \mathrm{l}$} & 7 & 1.08 & 0.01 \\
\hline 8 & & 8 & 1.01 & 0.09 \\
\hline 9 & & 9 & 0.96 & 0.03 \\
\hline 10 & & 10 & 0.79 & 0.01 \\
\hline 11 & & 11 & 1.02 & 0.01 \\
\hline 12 & & 13 & 1.92 & 0.03 \\
\hline 13 & & 14 & 0.94 & 0.01 \\
\hline 14 & & 15 & 2.29 & 0.09 \\
\hline 15 & & 16 & 2.19 & 0.10 \\
\hline 16 & & 17 & 1.37 & 0.08 \\
\hline 17 & & 18 & 5.81 & 0.04 \\
\hline 18 & & 19 & 2.25 & 0.01 \\
\hline 19 & & 20 & 2.61 & 0.03 \\
\hline 20 & & 21 & 2.43 & 0.02 \\
\hline 21 & & 22 & 2.20 & 0.02 \\
\hline 22 & & 23 & 2.37 & 0.13 \\
\hline 23 & & 24 & 1.77 & 0.04 \\
\hline 24 & & 25 & 2.03 & 0.01 \\
\hline 25 & & 26 & 2.06 & 0.02 \\
\hline 26 & CRM: BND & 27 & 2.07 & 0.01 \\
\hline 27 & 102.04 & 28 & 1.84 & 0.02 \\
\hline 28 & {$[\mathrm{~Pb}]=2 \mathrm{mg} / \mathrm{l}$} & 29 & 2.08 & 0.02 \\
\hline 29 & & 30 & 2.09 & 0.15 \\
\hline 30 & & 31 & 1.49 & 0.01 \\
\hline 31 & & 32 & 2.00 & 0.01 \\
\hline 32 & & 33 & 5.02 & 0.01 \\
\hline 33 & & 34 & 2.08 & 0.01 \\
\hline 34 & & 35 & 2.13 & 0.04 \\
\hline 35 & & 37 & 2.29 & 0.02 \\
\hline 36 & & 38 & 2.20 & 0.02 \\
\hline 37 & & 39 & 2.10 & 0.05 \\
\hline 38 & & 40 & 2.01 & 0.02 \\
\hline 39 & & 42 & 1.66 & 0.06 \\
\hline 40 & & 43 & 2.00 & 0.00 \\
\hline 41 & & 44 & 5.41 & 0.02 \\
\hline 42 & & 45 & 1.58 & 0.01 \\
\hline 43 & & 46 & 2.09 & 0.01 \\
\hline 44 & & 47 & 5.12 & 0.04 \\
\hline 45 & & 48 & 5.67 & 0.03 \\
\hline 46 & & 49 & 5.02 & 0.00 \\
\hline 47 & & 50 & 5.22 & 0.03 \\
\hline 48 & & 51 & 0.83 & 0.03 \\
\hline 49 & & 52 & 6.02 & 0.18 \\
\hline 50 & $\begin{array}{l}\text { CRIV: BND } \\
105.01\end{array}$ & 53 & 6.54 & 0.06 \\
\hline 51 & $\begin{array}{c}105.01 \\
{[\mathrm{Ph}]=5.01 \mathrm{mg} / \mathrm{l}}\end{array}$ & 54 & 5.34 & 0.01 \\
\hline 52 & {$[P D]=5.01 \mathrm{mg} / \mathrm{l}$} & 55 & 5.47 & 0.00 \\
\hline 53 & & 56 & 5.83 & 0.06 \\
\hline 54 & & 57 & 5.27 & 0.04 \\
\hline 55 & & 58 & 5.24 & 0.01 \\
\hline 56 & & 59 & 4.97 & 0.20 \\
\hline 57 & & 60 & 5.92 & 0.04 \\
\hline 58 & & 61 & 5.10 & 0.02 \\
\hline
\end{tabular}

Table 1. Details of the sample recipient laboratories and their results 


\begin{tabular}{ccccc}
\hline $\begin{array}{c}\text { SI. } \\
\text { No. }\end{array}$ & $\begin{array}{c}\text { Metal Solution } \\
\text { Sent (Marked as } \\
\text { C) }\end{array}$ & $\begin{array}{c}\text { Lab } \\
\text { Code } \\
\text { Number }\end{array}$ & $\begin{array}{c}\text { Mean } \\
\text { Value } \\
(\mathbf{m g} / \mathbf{l})\end{array}$ & $\begin{array}{c}\text { Standard } \\
\text { Deviation } \\
(\mathbf{m g} / \mathbf{l})\end{array}$ \\
\hline 59 & & 62 & 4.00 & 0.20 \\
60 & & 63 & 5.00 & 0.07 \\
61 & & 64 & 5.23 & 0.01 \\
62 & & 65 & 5.05 & 0.03 \\
63 & & 66 & 5.18 & 0.01 \\
64 & & 67 & 5.04 & 0.03 \\
\hline
\end{tabular}

\section{Result and Discussion of Statistical Analysis of PB Elemental Solution}

\subsection{Numerical Statistical Analysis}

As in this PT program the CRMs of elemental solutions have been distributed to the participating laboratories, so the certified value of the CRMs are used as the reference value. To see the scattering of the data, the results of the participants with standard uncertainty are presented in Figure 1(a)-(c) with the CRM reference value. The central line represents the reference value and the dotted lines above and below the central line is the dispersion attributed to the reference value (given in Table 1) of the $\mathrm{Pb}$ elemental solution. The bar line shows the individual result of the participant with standard uncertainty. It can be seen from the figures that laboratory code $6 ; 18,33,44$ and 46, 51 in case of $1 \mathrm{mg} / \mathrm{l}, 2 \mathrm{mg} / \mathrm{l}$ and $5.01 \mathrm{mg} / \mathrm{l}$ of $\mathrm{Pb}$ solutions respectively are far from the reference value which give the impression as outliers. In case of $1 \mathrm{mg} / \mathrm{l}$ result, the bar line for lab code $5 \& 6$ are significantly high implies much variation in the replicates. In this paper emphasis has been given to find out the outliers so as to assess the participant performance but not to ascertain the assigned value. Hence the data received from the participating laboratories have been evaluated by both numerical and graphical method mentioned above and the assessment of the outcome of different methods applied to the results is presented in this section. The results obtained from the Cochran's test were compared with the critical values of the Cochran's table and found that the laboratory codes $5 \& 8$ in case of $1 \mathrm{mg} / \mathrm{l}$; $15,16,17,23 \& 30$ in case of $2 \mathrm{mg} / 1$ and $52,59 \& 62$ in case of $5.01 \mathrm{mg} / \mathrm{l}$ of $\mathrm{Pb}$ elemental solution measurement are classified as outliers. Cochran's test considers only the within laboratories reproducibility/repeatability result so even though the laboratory results are quite far i.e. deviates $75 \%$ from the reference value is not considered as outlier. Rather the result which deviates only $1 \%$ from the reference value is found as outlier that can be reveals from the bar of the lab code 8 in figure 1(a). As Cochran's test is the intra laboratory variability test, so this method is not reliable for the outlier detection.

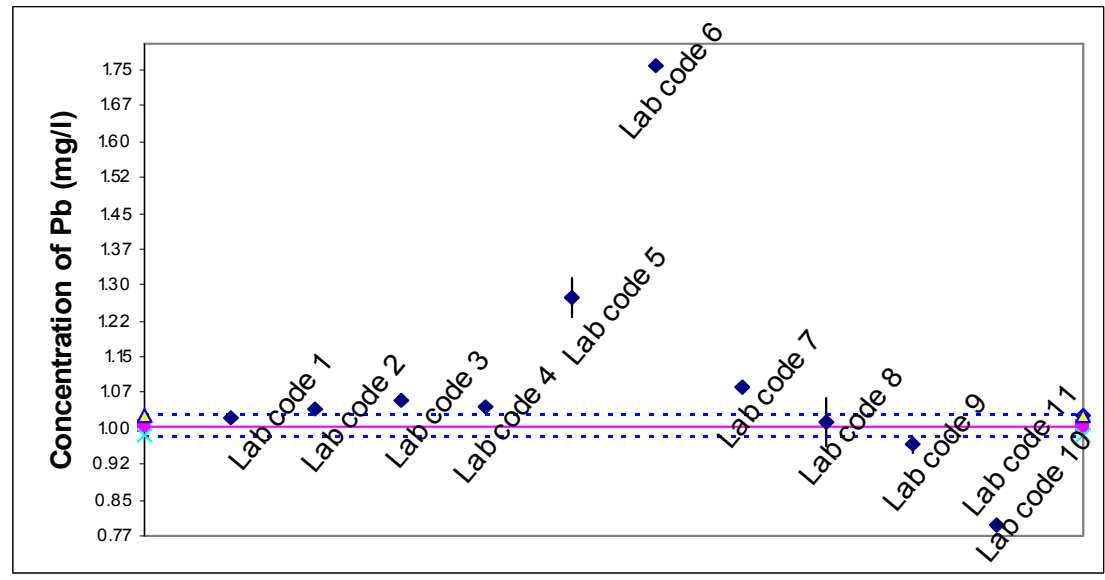

Figure 1(a). Reported result of the participant with lab code for Pb elemental solution $1 \mathrm{mg} / \mathrm{l}$

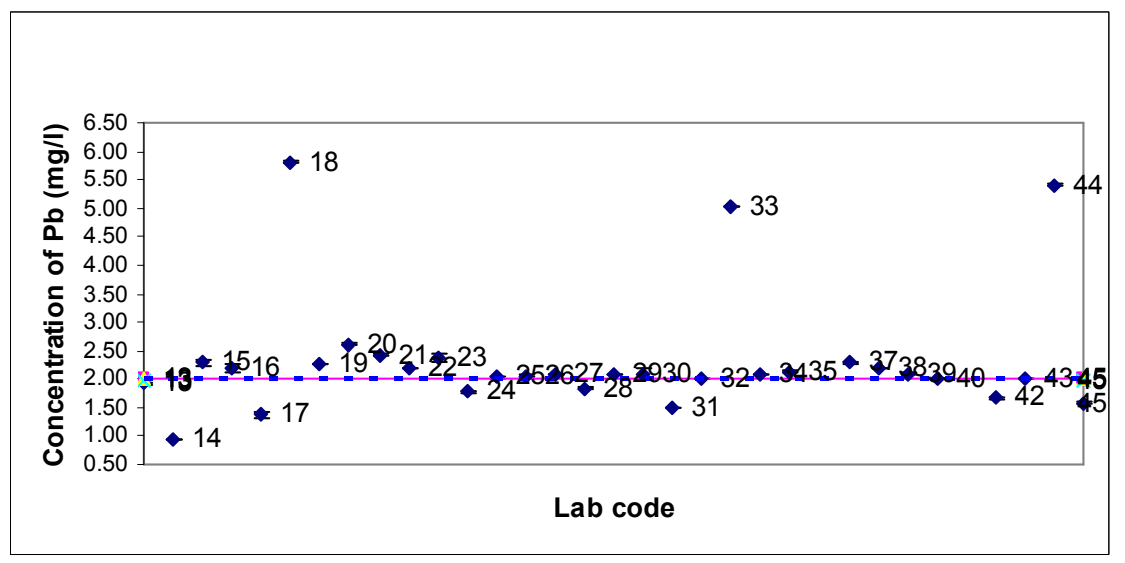

Figure 1(b). Reported result of the participant with lab code for Pb elemental solution $2 \mathrm{mg} / \mathrm{l}$ 


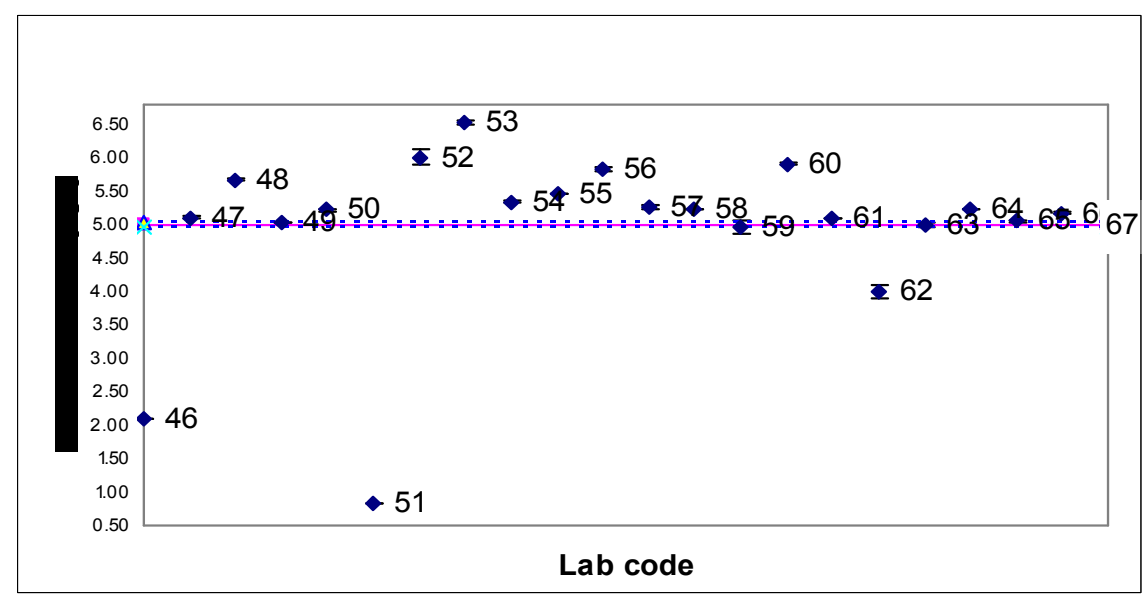

Figure 1(c). Reported result of the participant with lab code for Pb elemental solution $5.01 \mathrm{mg} / \mathrm{l}$

Table 2. Outliers detected by various statistical analysis

\begin{tabular}{|c|c|c|c|}
\hline \multirow{2}{*}{ Test carried out } & \multicolumn{3}{|c|}{ Lab code of detected outliers for measurement of $\mathrm{Pb}$ elemental solutions } \\
\hline & $1 \mathrm{mg} / \mathrm{l}$ & $2 \mathrm{mg} / \mathrm{l}$ & $5 \mathrm{mg} / \mathrm{l}$ \\
\hline Cochran's Test & 5,8 & $15,16,17,23,30$ & $52,59,62$ \\
\hline Grubb’s Test & 6 & $18,33,44$ & 46,51 \\
\hline Hampel Test & $5,6,10$ & $14,18,33,44$ & $46,51,53,62$ \\
\hline Classical approaches & Nil & 18 & 51 \\
\hline Median \& NIQR method (Robust z-score) & $5,6,10$ & $14,17,18,33,44$ & $46,51,53,62$ \\
\hline ISO 13528: Alogorithm A method & $5,6,10$ & $14,18,33,44$ & $46,51,53,62$ \\
\hline NATA Method & 5,8 & $15,16,23,30$ & $52,59,62$ \\
\hline NATA Method & $5,6,10$ & $14,17,18,31,33$ & $51,53,62$ \\
\hline
\end{tabular}

Similarly, Grubb's test is also not suitable method to find out outliers. This test was evaluated with considering two largest and two smallest values of the results and compared with the critical values of the Grubb's table. There is one number, three numbers and two numbers of results in case of 1,2 and $5.01 \mathrm{mg} / 1 \mathrm{~Pb}$ elemental solution respectively were evaluated as outlier in Grubb's test. In this test the highest deviation of the result of the laboratory code 6 is found to be $75 \%$ above from the reference value for $1 \mathrm{mg} / \mathrm{l}$ $\mathrm{Pb}$ elemental solution where as the laboratories code 18,33 , 44, 46, 51 for other two concentrations are reported strange values which give an impression that these laboratories have been biased with the other laboratory. There is less number of laboratories found as outlier in Grubb's test as compared to Cochran's test. The laboratories detected as outliers by Cochran's and Grubb's test for all the concentrations of $\mathrm{Pb}$ elemental solutions are shown in the table 2 .

Hampel's test which is known as Huber test [7] was carried out following the condition i.e. the deviation value from the median with the median of deviation of the data set to find out outlier. Hampel's test is more or less a robust test towards outlier detection as the median value of all the measurement is considered to find out outliers. The number of outlier detected by Hampel's test is more as compared to Cochran and Grubb's test in analysis of all the concentrations of $\mathrm{Pb}$ elemental solution. It was found that the result which is far from the reference value in the data set i.e. deviate at least $20 \%$ were detected as outlier and this method seems to be a good method for outlier detection. The outlier lab codes for all the concentrations of $\mathrm{Pb}$ are shown in table 2 .

\subsection{Graphical Statistical Analysis}

In PT, most often the results obtained from the participating laboratories are expressed in terms of z-score to present their performance. The $\mathrm{z}$-score of individual laboratory indicates how much its reported result differs from the reference/assigned value and identify as satisfactory, questionable and unsatisfactory results. In this paper to assess the laboratory performance, data received from the participating laboratories have been converted into the z-score by applying the statistical methods. According to the classical $\mathrm{z}$-score, the outliers result influence the mean value and standard deviation of the data set. By classical approach, maximum numbers of laboratories show z-score within acceptable range i.e. lies within z-score \pm 2 . In case of robust $z$-score calculation the median and the normalized inter quartile range (NIQR) of the data set have been considered. In this test laboratories 5,6 and 10 for 1 $\mathrm{mg} / \mathrm{l}, 14,17,18,33$ and 44 for $2 \mathrm{mg} / \mathrm{l}$ and 46, 51, 52 and 62 for $5.01 \mathrm{mg} / \mathrm{l}$ are showing unsatisfactory results. This is a very good method to find out the outliers as the median of the data set used in the calculation which does not influenced much by the result far from the reference value. The z-score obtained from the classical and robust method is tabulated in table 3. In ISO 13528: robust analysis of algorithm A method to get the robust estimates, initially the 
PT results were arranged in an increasing order and the absolute deviation from the median was calculated. Then by iteration i.e. updating the robust average $\left(x^{*}\right)$ and robust standard deviation $\left(s^{*}\right)$ several times the process converges so that the value does not change from one iteration to the next iteration till the third digit. The robust average is considered as the assigned value and the uncertainty value was derived by putting the robust standard deviation in Eq. 10. The consensus/assigned value with the standard deviation/uncertainty value derived by different methods along with the reference value are tabulated in Table 4 . The z-score was calculated using the robust estimates. The laboratory result which deviates up to $30 \%$ lower and higher from the reference value is not considered as outlier. The laboratories found as outlier by this method are similar with the laboratories found in case of Hampel's test. It is observed from the evaluation of the data; this is the best method to derive assigned value when the reference value of the analyte distributed for PT is not known.

Table 3. z-score obtained by classical and robust method

\begin{tabular}{|c|c|c|c|c|c|c|c|}
\hline SI. No. & Values mg/l & z-score Classical & $\begin{array}{l}\text { Z-score } \\
\text { Robust }\end{array}$ & SI. No. & Values mg/l & z-score Classical & z-score Robust \\
\hline lab 1 & 1.02 & -0.35 & -0.42 & lab 34 & 2.08 & -0.23 & 0.00 \\
\hline lab 2 & 1.03 & -0.29 & -0.12 & lab 35 & 2.13 & -0.19 & 0.19 \\
\hline lab 3 & 1.05 & -0.20 & 0.24 & lab 37 & 2.29 & -0.04 & 0.91 \\
\hline lab 4 & 1.04 & -0.26 & 0.00 & lab 38 & 2.20 & -0.13 & 0.49 \\
\hline lab 5 & 1.27 & 0.69 & 4.14 & lab 39 & 2.10 & -0.22 & 0.07 \\
\hline lab 6 & 1.75 & 2.67 & 12.83 & lab 40 & 2.01 & -0.30 & -0.33 \\
\hline lab 7 & 1.08 & -0.09 & 0.72 & lab 42 & 1.66 & -0.62 & -1.83 \\
\hline lab 8 & 1.11 & 0.03 & 1.26 & lab 43 & 2.00 & -0.31 & -0.36 \\
\hline lab 9 & 0.96 & -0.59 & -1.44 & lab 44 & 5.41 & 2.85 & 14.49 \\
\hline lab 10 & 0.79 & -1.27 & -4.44 & lab 45 & 1.58 & -0.69 & -2.18 \\
\hline lab 11 & 1.02 & -0.33 & -0.30 & lab 46 & 2.09 & -0.38 & -10.17 \\
\hline lab 13 & 1.92 & -0.38 & -0.70 & lab 47 & 5.12 & 0.12 & -0.27 \\
\hline lab 14 & 0.94 & -1.29 & -4.99 & lab 48 & 5.67 & 0.57 & 1.54 \\
\hline lab 15 & 2.29 & -0.04 & 0.90 & lab 49 & 5.02 & 0.05 & -0.59 \\
\hline lab 16 & 2.19 & -0.13 & 0.46 & lab 50 & 5.22 & 0.21 & 0.07 \\
\hline lab 17 & 1.37 & -0.89 & -3.10 & lab 51 & 0.83 & -3.30 & -14.28 \\
\hline lab 18 & 5.81 & 3.22 & 16.23 & lab 52 & 6.02 & 0.84 & 2.67 \\
\hline lab 19 & 2.25 & -0.07 & 0.74 & lab 53 & 6.54 & 1.26 & 4.38 \\
\hline lab 20 & 2.61 & 0.26 & 2.31 & lab 54 & 5.34 & 0.31 & 0.47 \\
\hline lab 21 & 2.43 & 0.09 & 1.51 & lab 55 & 5.47 & 0.41 & 0.88 \\
\hline lab 22 & 2.20 & -0.12 & 0.51 & lab 56 & 5.83 & 0.69 & 2.05 \\
\hline lab 23 & 2.37 & 0.03 & 1.25 & lab 57 & 5.27 & 0.25 & 0.23 \\
\hline lab 24 & 1.77 & -0.52 & -1.35 & lab 58 & 5.24 & 0.23 & 0.14 \\
\hline lab 25 & 2.03 & -0.28 & -0.22 & lab 59 & 4.97 & 0.01 & -0.75 \\
\hline lab 26 & 2.06 & -0.25 & -0.09 & lab 60 & 5.92 & 0.76 & 2.34 \\
\hline lab 27 & 2.07 & -0.24 & -0.04 & lab 61 & 5.10 & 0.11 & -0.33 \\
\hline lab 28 & 1.84 & -0.46 & -1.07 & lab 62 & 4.00 & -0.77 & -3.92 \\
\hline lab 29 & 2.08 & -0.23 & 0.00 & lab 63 & 5.00 & 0.03 & -0.66 \\
\hline lab 30 & 2.09 & -0.22 & 0.03 & lab 64 & 5.23 & 0.21 & 0.09 \\
\hline lab 31 & 1.49 & -0.78 & -2.57 & lab 65 & 5.05 & 0.07 & -0.48 \\
\hline lab 32 & 2.00 & -0.30 & -0.35 & lab 66 & 5.18 & 0.18 & -0.07 \\
\hline lab 33 & 5.02 & 2.48 & 12.76 & lab 67 & 5.04 & 0.07 & -0.51 \\
\hline
\end{tabular}

Table 4. Comparison of reference value with the mean, median, robust assigned value obtained by various statistical methods

\begin{tabular}{|c|c|c|c|c|c|c|c|c|}
\hline \multirow{2}{*}{$\begin{array}{l}\text { Reference } \\
\text { value of } \mathbf{P b} \\
\text { elemental } \\
\text { solution }(\mathrm{mg} / \mathrm{l}) \\
\text { at } 95 \% \\
\text { confidence } \\
\text { level }\end{array}$} & \multicolumn{2}{|c|}{ Mean value } & \multicolumn{2}{|c|}{ Median value } & \multicolumn{2}{|c|}{$\begin{array}{l}\text { Consessus value } \\
\text { (after elimination of outlier } \\
\text { obtained by Hampel's test) }\end{array}$} & \multicolumn{2}{|c|}{$\begin{array}{l}\text { Assigned value } \\
\text { (ISO } 13528 \text { method) }\end{array}$} \\
\hline & $\begin{array}{l}\text { Mean } \\
\text { value } \\
(\mathrm{mg} / \mathrm{l})\end{array}$ & $\begin{array}{c}\text { Standard } \\
\text { uncertainty } \\
(\mathrm{mg} / \mathrm{l})\end{array}$ & $\begin{array}{l}\text { Median } \\
\text { value } \\
\text { (mg/l) }\end{array}$ & NIQR (mg/l) & $\begin{array}{c}\text { Consensus } \\
\text { value } \\
\text { (mg/l) }\end{array}$ & NIQR (mg/l) & $\begin{array}{c}\text { Assigned } \\
\text { value (mg/l) }\end{array}$ & $\begin{array}{c}\text { Standard } \\
\text { uncertainty } \\
(\mathbf{m g} / \mathbf{l})\end{array}$ \\
\hline $1.00 \pm 0.01$ & 1.10 & 0.07 & 1.04 & 0.06 & 1.03 & 0.02 & 1.05 & 0.03 \\
\hline $2.00 \pm 0.01$ & 2.33 & 0.19 & 2.08 & 0.23 & 2.08 & 0.18 & 2.07 & 0.06 \\
\hline $5.01 \pm 0.04$ & 4.96 & 0.27 & 5.20 & 0.31 & 5.22 & 0.28 & 5.21 & 0.09 \\
\hline
\end{tabular}




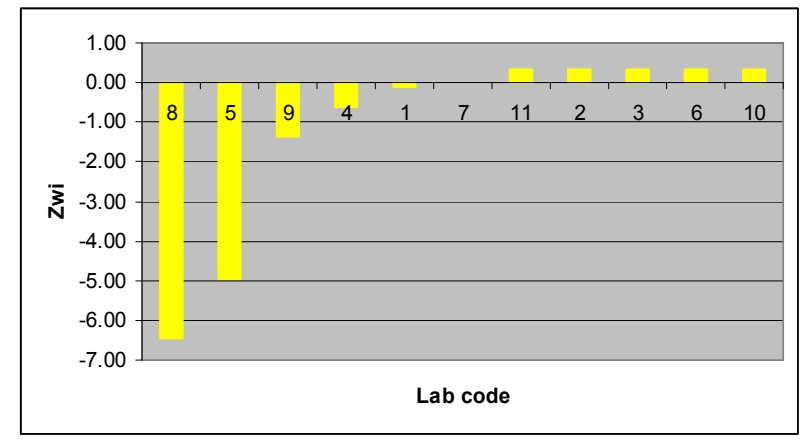

Figure 2(a). z-score within laboratories (Zwi) obtained by NATA method for Pb elemental solution $1 \mathrm{mg} / \mathrm{l}$

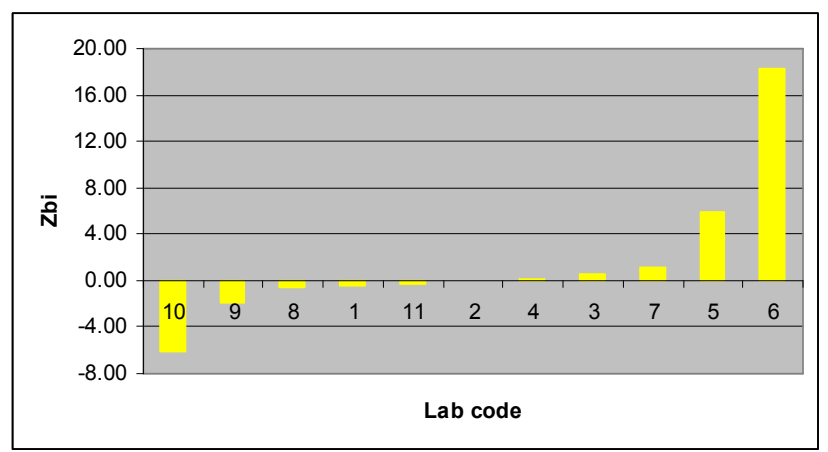

Figure 2(b). z-score between laboratories (Zbi) obtained by NATA method for Pb elemental solution $1 \mathrm{mg} / \mathrm{l}$

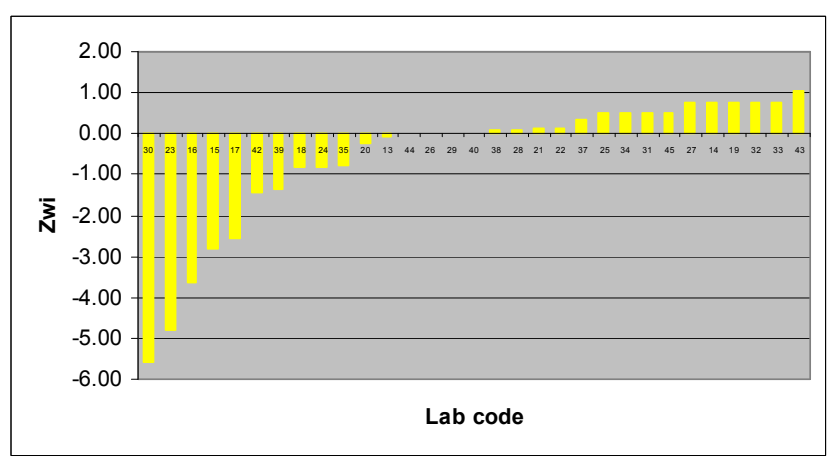

Figure 2(c). z-score within laboratories (Zwi) obtained by NATA method for Pb elemental solution $2 \mathrm{mg} / \mathrm{l}$

Data received from the participating laboratories have been evaluated quantitatively for their quality of measurement using NATA method also. For this purpose the PT data was processed to calculate two types of $z$ scores such as z-score within the laboratory (Zwi) and between the laboratories ( $\mathrm{Zbi}$ ) by integration of the seven summary statistics - number of the laboratories, median, normalized interquartile range (IQR), robust coefficient of variation $(\mathrm{CV})$, minimum, maximum and range [4]. A value of the z-scores within the laboratory indicates the variance in the data produced in the same laboratory and z-score between the laboratories indicates the variance in the data produced by different participating laboratories. The quality of the measurement increases with the decrease in the z-

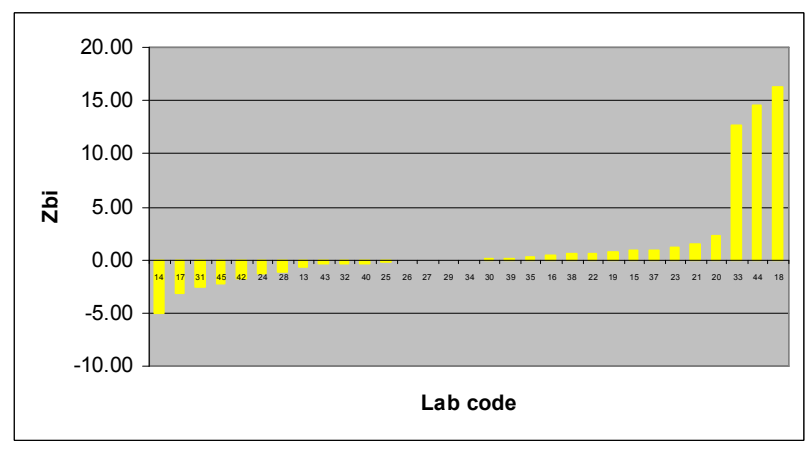

Figure 2(d). z-score between laboratories (Zbi) obtained by NATA method for Pb elemental solution $2 \mathrm{mg} / \mathrm{l}$

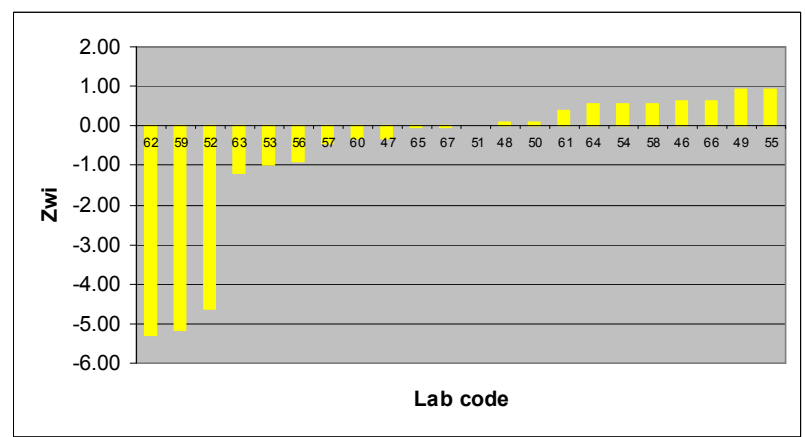

Figure 2(e). z-score within laboratories (Zwi) obtained by NATA method for Pb elemental solution $5.01 \mathrm{mg} / \mathrm{l}$

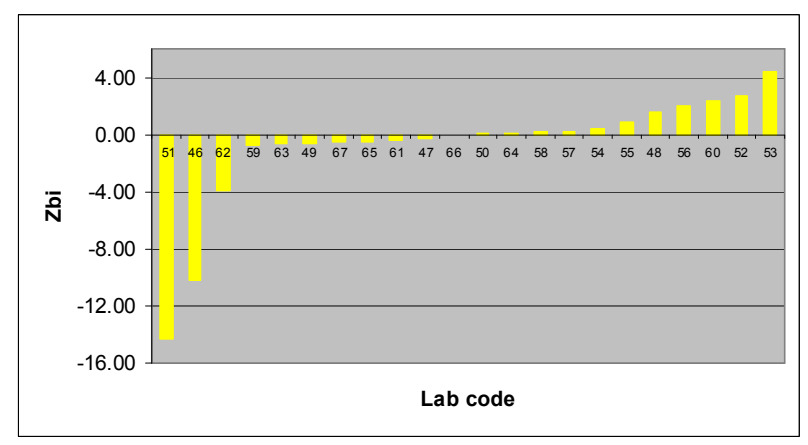

Figure 2(f). $z$-score between laboratories (Zbi) obtained by NATA method for Pb elemental solution $5.01 \mathrm{mg} / \mathrm{l}$

score value. The values of both the $z$-score within the laboratory and z-score between the laboratories has been calculated for all the concentrations of $\mathrm{Pb}$ solution and are plotted against the lab code (Figure 2(a) - (f)). From the chart of the z-score results each laboratory can compare easily its performance relative to their own and other laboratories results. Figure 2(a), (c) and (e) show that for the analysis of $\mathrm{Pb}$ solution the laboratory nos. 5, 8 for 1 $\mathrm{mg} / \mathrm{l} ; 15,16,23,30$ for $2 \mathrm{mg} / 1$ and $52,59,62$ for $5.01 \mathrm{mg} / 1$ concentration are having greater variance which Zwi is outside the range \pm 3 . Similarly, laboratory code nos. 5, 6, 10 for $1 \mathrm{mg} / 1 ; 14,17,18,31,33$ for $2 \mathrm{mg} / \mathrm{l}$ and lab code no. $51,53,62$ for $5.01 \mathrm{mg} / \mathrm{l}$ are exceeding Zbi value \pm 3 when the median value of individual laboratory is compared with 
the median value of all the participating laboratories [Figure 2(b), (d) and (f)]. Hence these laboratories having z-score outside the range \pm 3 are an indication of a problem with their results and are considered to be outlier laboratories for the analysis of $\mathrm{Pb}$ solution. The laboratory with code no. 17 in case of Zwi and 20, 42, 45, 52, 60 in case of Zbi exceed the cut off value of the z-score i.e. outside the range of \pm 2 and below \pm 3 ; which are advised to have a look into their result. There are 19 numbers of laboratories found as outlier by this method considering both the within and between laboratory data variability.

\subsection{Comparison of Statistical Methods Applied for Laboratories Performance}

The overall result of the statistical evaluation of the analysis of all the concentrations of $\mathrm{Pb}$ elemental solutions is compared in figure 3 which gives a clear idea about the percent of outliers found by each statistical method. Except lab code 17, the other laboratories found as outlier in the Cochran's test is totally matches with the outlier result of the within laboratory variance of NATA method. The percent of outlier in case of classical approach for calculation of z-score is very less i.e. $0,<4$ and $<5 \%$ for 1 , 2 and $5.01 \mathrm{mg} / \mathrm{l} \mathrm{Pb}$ solution respectively and it seems to be not suitable method for outlier detection as the mean of the data set is biased by the extreme result of the participant. There is much similarities in the outlier result obtained by Hampel's test, Median \& NIQR method, ISO 13528 method and only the between laboratory variance of NATA method in which the median value was considered for the z-score calculation. The median value does not affected by the absurd result given by the participant. More or less $30 \%$ of the results in all the concentrations of $\mathrm{Pb}$ solutions are found as outlier by NATA method.

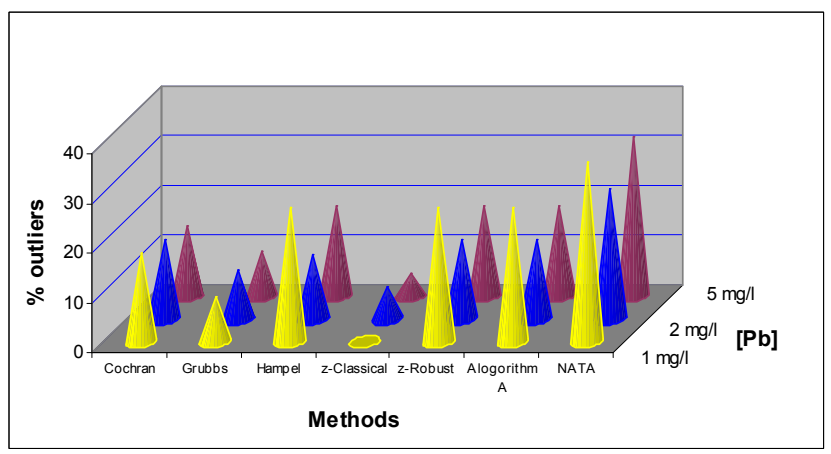

Figure 3. Comparison of statistical methods used for all the concentrations of $\mathrm{Pb}$ elemental solutions

Usually when the reference value of the measurand is not known in that case elimination of the outlier is a crucial task to set the assigned value. In that case the consensus value can be set after elimination of the outlier obtained by Hampel's test. The measurement results have been checked for the consensus value after eliminating the outliers obtained from Hampel's test and found very close to the reference value for the 1 and $2 \mathrm{mg} / \mathrm{l}$ of $\mathrm{Pb}$ solutions. The mean, median, assigned values of the data set are calculated as described above and presented in the table 4 . For 1 and 2 $\mathrm{g} / \mathrm{l} \mathrm{Pb}$ solution; the median, consensus and assigned values are almost same as the reference value but the mean value is quite far from the reference value for the same concentrations of $\mathrm{Pb}$ solution. This reveals that the mean value might be biased by more number of absurd results in the data set. In case of $5.01 \mathrm{mg} / \mathrm{l} \mathrm{Pb}$ solution, except the mean value, the set values obtained by other method are quite far from the reference value. The uncertainty value derived from ISO 13528: Algorithm A is very low for all the concentration of $\mathrm{Pb}$ solutions. From the comparison of the different statistical methods evaluated in this paper, it is revealed that NATA method is the most suitable method for the outlier detection for the present data set. However, it is difficult to predict a suitable statistical method for the determination of outlier as several factors depends on it such as structure of the data set, type of outliers, number of outliers in the dataset etc.

\section{Conclusions}

By comparing all the results it was observed that the common laboratories code numbers $5,6,8,10,14,15,16$, $17,18,23,30,33,44,46,51,52,53,59$ and 62 acquired the value of $z$-score out side the range \pm 3 in measurement of all the three concentration of $\mathrm{Pb}$ elemental solutions. All these laboratories considered as outlier and are advised to look into the matter and take necessary corrective action for over or under estimation of the results. In case of the measurement result of $1 \mathrm{mg} / 1 \mathrm{~Pb}$ solution, the outlier found in the higher side deviate $75 \%$ and the lower side deviate $21 \%$ from the reference value. The outlier laboratory codes $18,33,44$ are reported more than $5.01 \mathrm{mg} / \mathrm{l}$ in the higher side and laboratory code 14 reported less than $1 \mathrm{mg} / \mathrm{l}$ in the lower side for $2 \mathrm{mg} / \mathrm{l} \mathrm{Pb}$ solution measurement result. Similarly the laboratory codes 51,46 are found as outlier reported less than $2 \mathrm{mg} / \mathrm{l}$ instead of $5.01 \mathrm{mg} / \mathrm{l} \mathrm{Pb}$ solution measurement result. Among all the statistical methods NATA method is the best approach to find out outlier in a data set and for the performance assessment of the PT participant. Because it comprises both the within and between laboratory variance and moreover it is a robust analysis to calculate z-score which does not influenced by the extreme value of the data set. There is no systematic trend observed in the capability of measurement of the laboratories in analysis of lower and higher concentration of the $\mathrm{Pb}$ elemental solution even though different analytical methods and sophisticated instruments were used by the laboratories. More than $70 \%$ of laboratories are shown satisfactory performance for analysis of $\mathrm{Pb}$ out of 64 participants. The dissatisfactory performance of the laboratories might be due to not using a reference material of respective metal solution for calibration of the instrument/standardization of method. Therefore, it is advisable for all the PT participants to implement quality system in their laboratories and use of certified reference 
materials will be strongly recommended. The outcome of this proficiency testing clearly reveals that $\mathrm{Pb}$ elemental analysis of aqueous solution can be performed in many laboratories with high accuracy.

\section{Acknowledgement}

Authors are thankful to National Accreditation Board of Testing and Calibration Laboratories (NABL), India for providing financial support. Thanks are due to the Director, NPL for giving permission to publish this paper.

\section{References}

[1] ISO/IEC 17025, General Requirements for the Competence of Testing and Calibration Laboratories, International Standards Organization (ISO), Geneva, 1999.
[2] ISO/IEC 17043:2010(E) Conformity assessment-General requirements for proficiency testing. International Standards Organization, Geneva. First edition 2010-02-01.

[3] ILAC-G13: Guidelines for the requirements for the competence of proficiency testing schemes, 2000.

[4] New statistics for NATA's Proficiency Testing Programs, National Association of Testing Authorities (NATA), Australia, 1996.

[5] ISO 13528:2005(E) Statistical methods for use in proficiency testing by interlaboratory comparisons, International Standards Organization, Geneva. First edition 2005-09-01.

[6] Nordtest project No. 1483-99; 2000:35 methedology of inter-comparison Tests and statistical analysis of test results.

[7] Quality assurance and quality control in the analytical chemical laboratory: A practical approaches. Piotr Konieczka and Jacek Namiesnik. Taylor \& Francis Group, 2009. 